OPEN ACCESS

Edited by:

Malgorzata Gabriela Wasniewska, University of Messina, Italy

Reviewed by: Mariella Valenzise, University of Messina, Italy Artur Bossowski Medical University of Bialystok, Poland

${ }^{*}$ Correspondence: Anna Małgorzata Kucharska ankucharska@wum.edu.pl

Specialty section:

This article was submitted to Pediatric Endocrinology, a section of the journal Frontiers in Endocrinology

Received: 31 March 2020 Accepted: 11 May 2020 Published: 08 July 2020

Citation: Kucharska AM, Witkowska-Sẹdek E, Labochka D and Rumińska M (2020) Clinical and Biochemical Characteristics of Severe Hypothyroidism Due to Autoimmune

Thyroiditis in Children.

Front. Endocrinol. 11:364. doi: $10.3389 /$ fendo.2020.00364

\section{Clinical and Biochemical Characteristics of Severe Hypothyroidism Due to Autoimmune Thyroiditis in Children}

\author{
Anna Małgorzata Kucharska*, Ewelina Witkowska-Sȩdek, Dominika Labochka and \\ Małgorzata Rumińska
}

Department of Paediatrics and Endocrinology, Medical University of Warsaw, Warsaw, Poland

Introduction: In the majority of countries, autoimmune thyroiditis is the main cause of acquired hypothyroidism in children. Typically, the natural course of the disease is initially insidious and the diagnosis is incidental. There are some children who develop severe hypothyroidism without a proper diagnosis. The aim of the study was to analyze the clinical and biochemical profiles of children with severe primary hypothyroidism due to autoimmune thyroiditis.

Materials and Methods: We analyzed the records of 354 patients diagnosed between 2009 and 2019 with autoimmune thyroiditis. Only patients with TSH above $100 \mu \mathrm{lU} / \mathrm{mL}$, associated with decreased free thyroxine and the presence of antithyroid antibodies, were enrolled in the study. The analysis encompassed clinical symptoms, thyroid and biochemical status, bone age, and imaging.

Results: Twenty-six children were enrolled in the study. The mean age at diagnosis was $10.26 \pm 3.3$ years, with a female preponderance of 1.8:1. The most frequent symptom was growth impairment (77\%) and weight gain (58\%). Goiters were present in $42 \%$ of patients. Less common findings were pituitary hypertrophy (four patients) and hypertrichosis (three patients). Median values at the time of diagnosis were TSH $454.3 \mathrm{ulU} / \mathrm{ml}$ (295.0-879.4), anti-TPO antibodies 1,090 IU/ml, and anti-Tg antibodies $195 \mathrm{IU} / \mathrm{ml}$. Anti-TSHR ab were evaluated only in six out of the 26 patients. The characteristic biochemical profile was correlated with the grade of hypothyroidism, and the strongest correlations were found with CBC parameters, lipid profile, aminotransferases, and creatine.

Conclusion: In children with severe hypothyroidism, the most sensitive symptoms are growth arrest and weight gain despite the fact that, in some children, the auxological parameters at presentation could be within normal values for the population. The specific biochemical profile closely correlates to the severity of thyroid hormone deficiency and involves mostly erythropoiesis, liver function, and kidney function. Pituitary enlargement 
should be considered in each child with severe hypothyroidism. It is necessary to conduct prospective studies evaluating the actual frequency of anti-TSHR antibodies and pituitary enlargement in children with extremely high TSH, especially those presenting without goiters.

Keywords: severe autoimmune hypothyroidism, symptoms, hypertrichosis, pituitary hypertrophy, children

\section{INTRODUCTION}

Autoimmune thyroiditis (AIT) is the main cause of acquired hypothyroidism in children $(1,2)$. Typically, the natural course of disease is initially insidious and many patients are diagnosed incidentally before they present overt hypothyroidism (3). There are also some children who develop severe hypothyroidism for several months without a proper diagnosis.

The most common form of AIT is classic Hashimoto's disease with goiter-a high level of antithyroid antibodies and infiltration of the thyroid gland by macrophages and lymphocytes that form the specific thyroid lymphatic tissue (4). Some patients develop atrophic autoimmune thyroiditis, which is characterized by thyroid gland fibrosis, reduction of blood perfusion, and severe damage of thyroid tissue resulting in rapid progression of severe hypothyroidism. This atrophic thyroiditis is considered the form of autoimmune thyroid disease associated with lower levels of anti-thyroid antibodies in comparison to the goitrous form of AIT. It is typical that the majority of patients with atrophic AIT are diagnosed at the phase of advanced overt hypothyroidism (5). The diagnosis of AIT in those patients is usually delayed, probably because of the lack of goiter. In such children, some characteristic changes in the clinical and biochemical picture can be observed. Although the symptoms of hypothyroidism seem to be well-known, they are still often overlooked. Stereotypically, a child with hypothyroidism is an obese, short, slow, and sleepy patient with a goiter. Nonetheless, particular symptoms usually have a specific pattern: in children with hypothyroidism, there is an observed redistribution of subcutaneous tissue due to myxedema rather than simple obesity; growth arrest is more characteristic than absolute short stature; and weight gain is observed with normal or even reduced food intake. Some patients also present non-specific symptoms like fainting and headaches. In laboratory tests, the most characteristic abnormalities are lipid disorders $(6)$ and anemia $(7,8)$, but in some cases liver (9) and kidney (10) function could also be impaired.

The aim of our study was to analyze the clinical and biochemical profiles of children with severe primary hypothyroidism due to autoimmune thyroiditis.

\section{MATERIALS AND METHODS}

The study was retrospective. The medical records of 354 patients with AIT diagnosed between 2009 and 2019 in our institution were reviewed. Only patients with severe hypothyroidism (SH) were enrolled in the study. The criteria of inclusion were thyroid-stimulating hormone (TSH) value above $100 \mu \mathrm{IU} / \mathrm{mL}$ associated with free thyroxine (fT4) concentration below reference values and the presence of antithyroid antibodies: anti-thyroid peroxidase antibodies (anti-TPO ab) and/or antithyroglobulin antibodies (anti-Tg ab). Twenty-six patients (17 girls, nine boys) aged $10.26 \pm 3.3$ years met these criteria.

Serum concentrations of TSH, fT4, free triiodothyronine (fT3), anti-Tg ab, anti-TPO ab, aspartate aminotransferase (AST), alanine aminotransferase (ALT), creatinine, urea, fasting glucose, total cholesterol (total-C), low-density lipoprotein cholesterol (LDL-C), high-density lipoprotein cholesterol (HDLC), triglycerides (TG), and complete blood cell count (CBC) were analyzed. TSH receptor antibodies (TSHR ab) were measured in six out of 26 patients. Bone age (BA) using the Greulich and Pyle method (11) was evaluated in 14 out of 26 patients. An ultrasound of the thyroid gland was performed in each patient using 7.5-11 MHz linear transducer. In patients with specific indications, magnetic resonance imaging of pituitary gland was also performed.

The study was approved by the Bioethics Committee at the Medical University of Warsaw.

\section{Biochemical Analysis}

The serum concentrations of TSH, fT4, fT3, anti-Tg ab, and anti-TPO ab were measured by the immunofluorescence method using the Architect i1000SR Analyzer (Abbott Diagnostics, Abbott Park, Illinois, USA). The anti-TSHR ab levels were measured by electrochemiluminescence immunoassay (ECLIA) with the Cobas e801 Analyzer (Diagnostics Roche, Basel, Switzerland). ALT and AST activity, creatinine, and urea concentrations were measured by the dry chemistry method using Vitros 5600 Analyzer (Ortho Clinical Diagnostics, Raritan, New Jersey, USA). The glomerular filtration rate (GFR) was calculated using creatinine level, age, sex, and height by Bedside Schwartz method (12).

Fasting glucose was determined in blood serum using Vitros 5600 Analyzer (Ortho Clinical Diagnostics, Raritan, New Jersey, USA). The lipid profile parameters were determined using Vitros 5600 Analyzer (Ortho Clinical Diagnostics, Raritan, New Jersey, USA). CBC was measured in blood collected in EDTA samples using Sysmex-XN-1000i hematological analyzer (Sysmex Europe, Norderstedt, Germany): red blood cell (RBC) count, hemoglobin $(\mathrm{Hgb})$, mean corpuscular volume (MCV), mean corpuscular hemoglobin $(\mathrm{MCH})$, mean corpuscular hemoglobin concentration (MCHC), total white blood cell (WBC) count, and platelet (PLT) count. Blood samples were obtained from patients after overnight fasting.

Reference values of analyzed laboratory parameters are shown in Table 1. 
TABLE 1 | Average values of all evaluated biochemical parameters in SH children.

\begin{tabular}{|c|c|c|}
\hline Parameter & Results & Reference limits \\
\hline \multicolumn{3}{|l|}{ Thyroid } \\
\hline $\mathrm{TSH}(\mu \mathrm{IU} / \mathrm{ml})$ & $454.3(310.4-899.0)$ & $0.58-3.59$ \\
\hline fT4 (ng/dl) & $0.39(0.39-0.43)$ & $0.84-1.47$ \\
\hline fT3 (pg/ml) & $1.48 \pm 0.66$ & $2.33-4.35$ \\
\hline $\operatorname{Tg}$ ab (IU/I) & $934.0(197.4-1902.7)$ & $<4.1$ \\
\hline TPO ab (IU/I) & $195.4(38.3-647.1)$ & $<5.6$ \\
\hline \multicolumn{3}{|l|}{ Liver } \\
\hline ALT (U/I) & $49.0(25.0-108.0)$ & $10-30$ \\
\hline AST (U/I) & $73.0(41.0-98.0)$ & $10-40$ \\
\hline Fasting glucose (mg/dl) & $81.7 \pm 8.0$ & $70-99$ \\
\hline \multicolumn{3}{|l|}{ Kidneys } \\
\hline Creatinine (mg/dl) & $0.7(0.6-0.8)$ & $0.2-0.7$ \\
\hline Urea (mg/dl) & $28.1 \pm 7.0$ & $15-36.4$ \\
\hline \multicolumn{3}{|l|}{ Lipids } \\
\hline total-C (mg/dl) & $255.0(214.0-343.0)$ & $<170$ \\
\hline LDL-C (mg/dl) & $170.4(145.0-244.0)$ & $<110$ \\
\hline $\mathrm{HDL}-\mathrm{C}(\mathrm{mg} / \mathrm{dl})$ & $57.6 \pm 22.9$ & $>45$ \\
\hline $\mathrm{TG}(\mathrm{mg} / \mathrm{dl})$ & $109.5(67.0-173.0)$ & $<90$ \\
\hline \multicolumn{3}{|l|}{ СвС } \\
\hline $\operatorname{RBC}\left(\times 10^{6} / \mu \mathrm{l}\right)$ & $4.1 \pm 0.6$ & $4.7-6.1$ \\
\hline $\mathrm{Hgb}(\mathrm{g} / \mathrm{dl})$ & $12.0 \pm 1.5$ & $14-18$ \\
\hline MCV (fl) & $87.8 \pm 5.3$ & $78-95$ \\
\hline $\mathrm{MCH}(\mathrm{pg})$ & $29.2 \pm 1.7$ & $26-32$ \\
\hline $\mathrm{MCHC}(\mathrm{g} / \mathrm{dl})$ & $33.4 \pm 1.0$ & $31-35$ \\
\hline $\operatorname{WBC}\left(\times 10^{3} / \mu \mathrm{l}\right)$ & $6.7 \pm 2.0$ & $4-10$ \\
\hline $\operatorname{PLT}\left(\times 10^{3} / \mu \mathrm{l}\right)$ & $256.8 \pm 64.5$ & $150-400$ \\
\hline
\end{tabular}

Data are presented as mean \pm standard deviation or median with interquartile range as appropriate.

\section{Statistical Analysis}

Statistical analysis was performed using Statistica 13.1. Data was checked by the Shapiro-Wilk normality test. Results were reported as means \pm standard deviation (SD), median and interquartile ranges (IR), or as percentages, as appropriate. Correlations between variables were evaluated using the Spearman's correlation analysis for nonnormally distributed data and the Pearson's correlation test for normally distributed data. A $p<0.05$ was considered significant.

\section{RESULTS}

\section{Clinical Symptoms in SH Children}

The mean age at diagnosis was 10.26 (range 3.0-14.85), with girls' preponderance 1.8:1 (17:9). Growth arrest was the most frequent symptom (77\%), whereas absolute short stature (height $<3$ rd percentile for Polish population) was present only in $38 \%$. The second most frequent symptom was weight gain, reported in $58 \%$ of patients; simultaneously, absolute obesity was found in $38 \%(n=10)$ of patients (Table 2$)$. Only 11 out of 26 patients $(42 \%)$ had a goiter confirmed by ultrasound volume

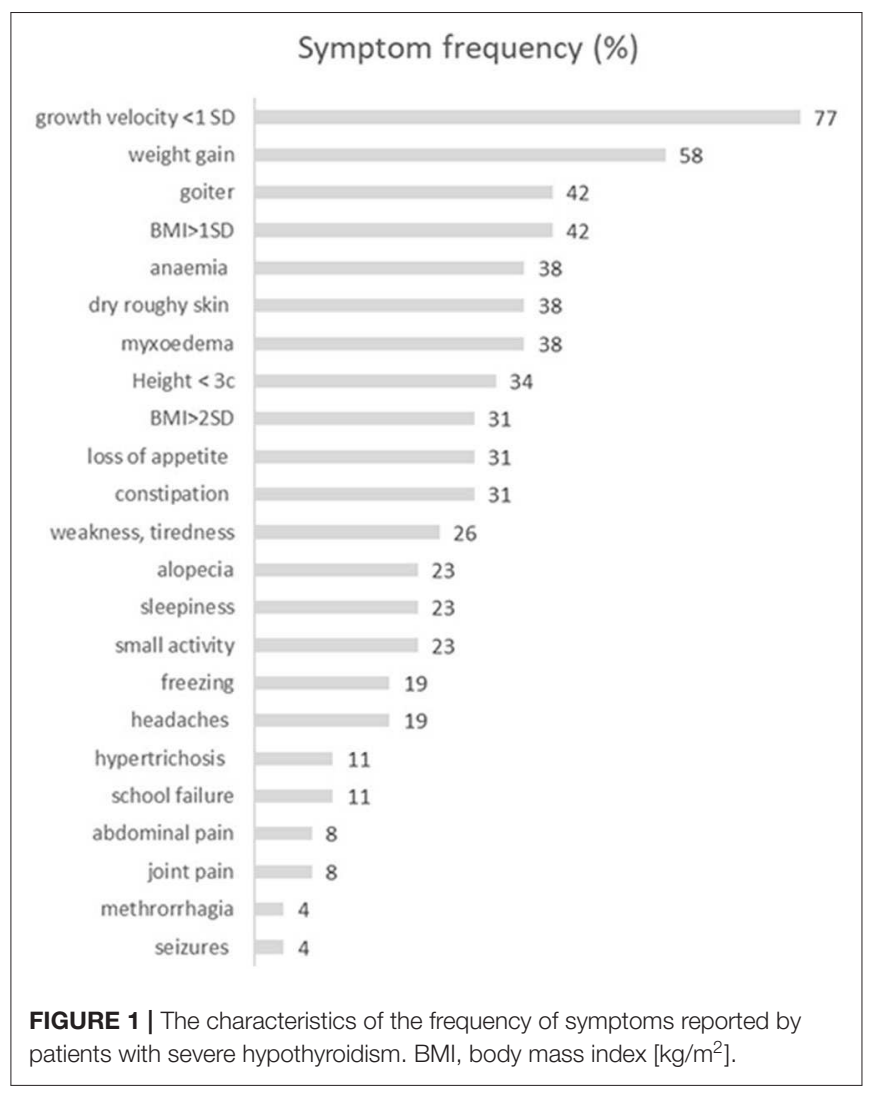

evaluation (Figure 1). The rarest symptoms were headaches, reported by four (15\%) patients, and among them, seizures in one patient $(4 \%)$. In those four patients, the CNS imaging was performed and anterior pituitary hypertrophy of variable grade was found without focal changes. Three patients had substantial hypertrichosis on the whole skin area, which disappeared when euthyroidism was achieved again. The characteristics of all clinical symptoms and findings in the $\mathrm{SH}$ children are presented in Figure 1. We also analyzed the diagnostic delay in $\mathrm{SH}$ children. The mean putative time from the occurrence of the first symptoms to the moment of diagnosis ranged from 6 months to 3 years.

\section{Laboratory Findings}

The evaluation of CBC revealed that $38 \%(n=10)$ of patients had reduced $\mathrm{RBC}, 42 \%(n=11)$ had decreased $\mathrm{Hb}$ value, and $\mathrm{MCV}$ in the majority of our patients was normal or slightly increased, with only one child having low MCV value.

Average values of laboratory results in all SH children are presented in Table 1. Parameters of lipid profile and kidney and liver function are shown in Table 3.

\section{Relations of TSH, fT4, and fT3 Levels With Other Biochemical Parameters and CBC}

In $\mathrm{SH}$ children, TSH levels were significantly positively correlated with AST $(R=0.46, p=0.026)$ and urea 
TABLE 2 | The auxological characteristics and hormonal and antibodies profile in patients with severe hypothyroidism.

\begin{tabular}{|c|c|c|c|c|c|c|c|c|c|c|c|c|c|c|}
\hline No & $\begin{array}{c}\text { Age } \\
\text { (years) }\end{array}$ & Sex & $\begin{array}{c}\text { TSH } \\
\text { (mIU/I) }\end{array}$ & fT4 (ng/dl) & $\begin{array}{c}\text { fT3 } \\
\text { (pg/ml) }\end{array}$ & $\begin{array}{c}\text { Anti-TPO } \\
(n \mathrm{l}<5.6)\end{array}$ & $\begin{array}{l}\text { Anti-Tg } \\
(n l<4.1)\end{array}$ & $\begin{array}{c}\text { Anti-TSHR } \\
\text { (positive } \\
>1.75 \mathrm{IU} / \mathrm{L} \text { ) }\end{array}$ & Goiter & $\begin{array}{c}\text { Bone age } \\
\text { (years) }\end{array}$ & $\begin{array}{l}\text { Height } \\
\text { SDS }\end{array}$ & $\begin{array}{c}\text { BMI } \\
\left(\mathrm{kg} / \mathrm{m}^{2}\right)\end{array}$ & $\begin{array}{c}\text { BMI } \\
\text { (SDS) }\end{array}$ & $\begin{array}{l}\text { Puberty } \\
\text { Tanner } \\
\text { scale }\end{array}$ \\
\hline 1 & 3 & $\mathrm{~F}$ & $>1,000$ & 0.41 & 1.4 & 49.0 & 17.0 & & Yes & 2 & -3.99 & 19.1 & 2.42 & B1P1 \\
\hline 2 & 4.59 & $\mathrm{~F}$ & 279.64 & 0.43 & 2.37 & 9340.9 & 61.2 & & No & & 0.16 & 28.9 & 8.50 & B1P1 \\
\hline 3 & 5.34 & $\mathrm{~F}$ & 859.74 & $<0.4$ & 0.99 & 140.0 & 2630.6 & & No & 2.5 & -1.8 & 19.6 & 2.39 & B1P1 \\
\hline 4 & 5.67 & $M$ & 534.45 & $<0.4$ & 0.99 & 4899.6 & 143.6 & & No & 4 & -2.13 & 14.9 & -0.54 & G1P1 \\
\hline 5 & 6.75 & $\mathrm{~F}$ & 332.4 & 0.4 & 1.6 & 2001.0 & 1400.0 & & Yes & 6 & -1.29 & 18.3 & 1.21 & B1P1 \\
\hline 6 & $8.5^{\text {twin }}$ & $\mathrm{F}$ & $>1,000$ & 0.15 & 0.92 & 187.0 & 36.8 & 0.8 & No & 3.5 & -3.5 & 24.5 & 3.18 & B1P1 \\
\hline 7 & $8.5^{\text {twin }}$ & $\mathrm{F}$ & 359.0 & 0.48 & 2.74 & 383.6 & 416.9 & 0.8 & No & 5 & -2.4 & 21.7 & 2.04 & B1P1 \\
\hline 8 & 8.59 & $\mathrm{~F}$ & 171.22 & 0.5 & 2.52 & 7.7 & 250.9 & & Yes & & 1.06 & 30.4 & 4.59 & B1P1 \\
\hline 9 & 9.08 & $\mathrm{~F}$ & $>1,000$ & $<0.4$ & 0.99 & 65.5 & 784.8 & 1.8 & No & 8 & -1.53 & 22.2 & 1.75 & B1P1 \\
\hline 10 & 9.67 & M & 278.37 & 0.45 & 2.5 & 2756.7 & 283.5 & & Yes & & -0.34 & 20.3 & 1.04 & G1P1 \\
\hline 11 & 10 & $\mathrm{~F}$ & 561.43 & $<0.4$ & 0.99 & 124.5 & 26.6 & 0.33 & No & & 0.18 & 22.2 & 1.75 & B1P1 \\
\hline 12 & 10 & $\mathrm{~F}$ & 316.97 & $<0.4$ & 1.49 & 2668.9 & 440.8 & & No & 8 & -1.8 & 24.3 & 2.47 & B1P1 \\
\hline 13 & 10.17 & $\mathrm{~F}$ & 355.78 & $<0.4$ & 1.31 & 1804.4 & 15.7 & & No & & -0.36 & 23.4 & 1.96 & B1P1 \\
\hline 14 & 10.5 & $M$ & 134.59 & 0.48 & 1.86 & 541.4 & 225.2 & & No & 9 & 1.66 & 24.8 & 2.45 & G1P1 \\
\hline 15 & 10.58 & M & 362.13 & 0.51 & 1.49 & 476.1 & 29.8 & & No & & -1.3 & 23.5 & 1.65 & G1P2 \\
\hline 16 & 11.68 & $M$ & 962.85 & $<0.4$ & 1.11 & 1185.8 & 554.8 & 0.8 & No & 8.5 & 2.17 & 18.6 & 0.15 & G1P1 \\
\hline 17 & 11.75 & $\mathrm{~F}$ & 899.0 & 0.04 & 0.25 & 1589.7 & 1761.0 & 0.77 & Yes & & -1.06 & 24.3 & 1.92 & B2P2 \\
\hline 18 & 12 & $\mathrm{~F}$ & $>1,000$ & $<0.4$ & 1.49 & 653.0 & 69.7 & & Yes & & -0.21 & 18.0 & -0.36 & B2P2 \\
\hline 19 & 12.09 & $\mathrm{M}$ & 613.39 & $<0.4$ & 0.99 & 1723.3 & 21.9 & & No & 11 & -2.06 & 25.9 & 2.08 & G2P2 \\
\hline 20 & 12.17 & $\mathrm{M}$ & 447.21 & $<0.4$ & 1.08 & 2806.2 & 739.4 & & Yes & & 0.06 & 22.5 & 1.19 & G2P2 \\
\hline 21 & 13.42 & $\mathrm{~F}$ & 133.94 & 0.41 & 2.18 & 233.2 & 158.0 & & Yes & & -1.46 & 17.1 & 0.88 & B3P3 \\
\hline 22 & 13.84 & $\mathrm{~F}$ & 461.48 & $<0.4$ & 1.1 & 1584.7 & 3712.0 & & Yes & 12.5 & -3.05 & 25.7 & 1.86 & B3P3 \\
\hline 23 & 14.67 & M & 310.4 & $<0.4$ & 0.99 & 207.7 & 39.8 & & No & & -0.22 & 25.8 & 2.17 & G3P3 \\
\hline 24 & 14.67 & $\mathrm{~F}$ & 561.98 & 0.36 & 0.98 & 873.3 & 45.8 & & Yes & 12 & -3.6 & 19.1 & -0.37 & B3P4 \\
\hline 25 & 14.67 & $\mathrm{~F}$ & 100.28 & 0.49 & 1.93 & 994.6 & 165.5 & & Yes & & 0.61 & 19.1 & -0.38 & B4P4 \\
\hline 26 & 14.85 & $\mathrm{M}$ & $>1,000$ & 0.22 & 0.74 & 88.8 & 15.5 & & no & 12.5 & -2.1 & 21.5 & 1.04 & G2P3 \\
\hline
\end{tabular}

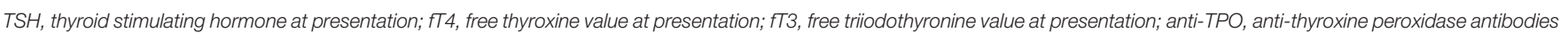

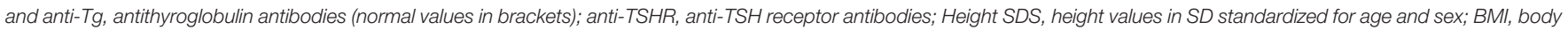
mass index; BMI SDS, BMI values in SD standardized for age and sex; B, breast development; P, pubic hair development. Patients No. 6 and 7. were monozygotic twins.

levels $(R=0.50, p=0.043)$. Negative correlations were found between TSH and RBC $(R=-0.75, p<0.0001)$ and between TSH and $\operatorname{Hgb}(R=-0.74, p<0.0001)$. TSH concentrations and MCV were positively correlated $(R$ $=0.46, p=0.019)$. Surprisingly, lipid profile turned out to not be significantly correlated with TSH value in $\mathrm{SH}$ children, although lipid parameters were highly increased (Tables 1, 3).

Free T4 levels were strongly negatively correlated with total$\mathrm{C}(R=-0.66, p=0.001)$ and LDL-C $(R=-0.61, p=0.009)$. Positive correlations were found between fT4 and certain CBC parameters such as $\mathrm{RBC}(R=0.45, p=0.023), \operatorname{Hgb}(R=$ $0.45, p=0.024)$, MCHC $(R=0.49, p=0.015)$, and PLT $(R=0.46, p=0.021)$. Free $\mathrm{T} 4$ concentration was negatively correlated with $\mathrm{MCV}(R=-0.57, p=0.003)$. Unfortunately, the evaluation of fT4 associations was limited, because in most patients at diagnosis we received the laboratory result of fT4 concentration as a value of " $<0.4 \mathrm{ng} / \mathrm{dl}$ " (Table 2), so for statistical calculations we determined the value arbitrarily as $0.39 \mathrm{ng} / \mathrm{dl}$.
We found a statistically significant negative correlation between fT3 levels and ALT $(R=0.46, p=0.046)$ and AST $(R$ $=-0.68, p=0.001)$. A strong negative correlation was found between $\mathrm{fT} 3$ and total-C $(\mathrm{R}=-0.67, p=0.002)$. Free T3 also correlated with $\mathrm{CBC}$ parameters: positively with $\mathrm{RBC}(R=0.53$, $p<0.05)$ and $\operatorname{Hgb}(R=0.47, p=0.031)$, and negatively with $\operatorname{MCV}(R=-0.58, p<0.05)$ and $\operatorname{MCH}(R=-0.45, p<0.05)$.

Bone age was delayed more than 1 year in nine out of 14 children in whom it was determined. The median difference between chronological age and BA was 0.4 years, with the range from 0 to 5 years. We found a significant negative correlation between TSH value and absolute BA $(R=-0.55, p=0.040)$, but no correlation between TSH and degree of BA delay (delta in years) $(p=0.08)$.

No relationships between anti-Tg ab or anti-TPO ab and any evaluated parameter were found in our study. Antibodies against TSHR were evaluated only in six out of $26 \mathrm{SH}$ patients at the presentation and in one of them the value was positive: $1.8 \mathrm{IU} / \mathrm{l}$ (by the cut-off $1.75 \mathrm{IU} / \mathrm{l}$ ). None of our patients had thyroid ophthalmopathy. 
TABLE 3 | Liver and kidney function tests in children with severe hypothyroidism.

\begin{tabular}{|c|c|c|c|c|c|c|c|c|c|c|c|}
\hline \multirow[t]{2}{*}{ No } & \multirow{2}{*}{$\begin{array}{c}\text { Age } \\
\text { (years) }\end{array}$} & \multirow{2}{*}{$\begin{array}{c}\text { TSH } \\
\text { (mIU/L) }\end{array}$} & \multirow{2}{*}{$\begin{array}{c}\text { ALT } \\
(U / L)\end{array}$} & \multirow{2}{*}{$\begin{array}{l}\text { AST } \\
\text { (U/L) }\end{array}$} & \multirow{2}{*}{$\begin{array}{l}\text { Creatynine } \\
\text { (mg/dl) }\end{array}$} & \multirow{2}{*}{$\begin{array}{c}\text { Urea } \\
\text { (mg/dl) }\end{array}$} & \multirow{2}{*}{$\begin{array}{c}\text { GFR } \\
\left(\mathrm{ml} / \mathrm{min} / 1.73 \mathrm{~m}^{2}\right)\end{array}$} & \multicolumn{4}{|c|}{ Lipid profile } \\
\hline & & & & & & & & $\begin{array}{l}\text { Total-C } \\
\text { (mg/dl) }\end{array}$ & $\begin{array}{l}\text { HDL-C } \\
\text { (mg/dl) }\end{array}$ & $\begin{array}{l}\text { LDL-C } \\
\text { (mg/dl) }\end{array}$ & $\begin{array}{c}\mathrm{TG} \\
(\mathrm{mg} / \mathrm{dl})\end{array}$ \\
\hline 1 & 3 & $>1,000$ & 62 & 90 & 0.6 & & 56.4 & 183 & 27 & 134.8 & 106 \\
\hline 2 & 4.6 & 279.64 & 25 & 39 & & & & 221 & & & \\
\hline 3 & 5.3 & 859.74 & 114 & 133 & 0.7 & 33 & 60.8 & 613 & 88 & 494.4 & 153 \\
\hline 4 & 5.7 & 534.45 & 49 & 85 & 0.7 & 27 & 61.7 & 235 & 58 & 146 & 153 \\
\hline 5 & 6.7 & 332.4 & 52 & 58 & 0.6 & 30 & 77.8 & 286 & 85 & 189.6 & 57 \\
\hline 6 & 8.5 & $>1,000$ & 25 & 49 & 0.5 & 28 & 93.3 & 230 & 36 & 145 & 119 \\
\hline 7 & 8.5 & 359.0 & 19 & 43 & 0.5 & 39 & 98.3 & 208 & 50 & 148 & 48 \\
\hline 8 & 8.6 & 171.22 & 21 & 29 & 0.6 & 23 & 94.2 & 214 & & & \\
\hline 9 & 9.1 & $>1,000$ & 139 & 98 & & & & 289 & 86 & 192.8 & 51 \\
\hline 10 & 9.7 & 278.37 & 151 & 86 & 0.6 & 21 & 94.2 & 214 & 30 & & 477 \\
\hline 11 & 10 & 561.43 & 44 & 92 & 0.8 & 27 & 72.8 & 411 & 51 & 348 & 81 \\
\hline 12 & 10 & 316.97 & 35 & 46 & 0.5 & 27 & 61.4 & & & & \\
\hline 13 & 10.2 & 355.78 & 48 & 55 & 0.9 & 27 & 63.8 & 400 & 27 & 195.4 & 296 \\
\hline 14 & 10.5 & 134.59 & & & & & & 189 & 62 & 114.6 & 62 \\
\hline 15 & 10.6 & 362.13 & & & 0.8 & 28 & 69.2 & 281 & & & 224 \\
\hline 16 & 11.7 & 962.85 & 108 & 144 & 1.1 & 38 & 50.7 & 253 & 71 & 156 & 58 \\
\hline 17 & 11.75 & 899.0 & 59 & 101.7 & 1.1 & 41 & 53.7 & 343 & 23 & 244 & 383 \\
\hline 18 & 12 & $>1,000$ & 26 & 41 & & & & 283 & & & 162 \\
\hline 19 & 12.1 & 613.39 & 113 & 128 & 1.1 & 41 & 52.4 & 375 & 84 & 254 & 113 \\
\hline 20 & 12.2 & 447.21 & 97 & 98 & 0.8 & 19 & 79.5 & 366 & 57 & 272 & 184 \\
\hline 21 & 13.4 & 133.96 & 24 & 40 & 0.6 & 14 & 106.0 & 208 & 78 & 114.8 & 76 \\
\hline 22 & 13.8 & 461.48 & 16 & 25 & 0.4 & & 146.6 & 255 & 80 & 160.6 & 72 \\
\hline 23 & 14.7 & 310.4 & 82 & 159 & 1.5 & 25 & 45.9 & & & & \\
\hline 24 & 14.7 & 561.98 & 108 & 73 & 0.8 & & 85.9 & & & & \\
\hline 25 & 14.7 & 100.28 & 14 & 16 & 0.8 & 31 & 86.2 & 164 & 44 & 99.4 & 103 \\
\hline 26 & 14.9 & $>1,000$ & & & & & & & & & \\
\hline
\end{tabular}

\section{DISCUSSION}

\section{Clinical Symptoms}

Growth arrest in children is the most sensitive symptom of thyroid hormone deficiency because of the thyroid's strong impact on growth hormone synthesis and action. Nevertheless, in our group of patients, only $77 \%$ reported decreased growth velocity as the main problem. We can easily explain this observation taking into consideration the age of our patients and their pubertal status. All patients in whom the growth retardation was not reported were at the age of 13-14 years and had almost reached their final height and completed their pubertal development. Additionally, comparing the number of children with growth inhibition and absolute short stature, we can conclude that growth arrest, rather than height below the third percentile, is the most sensitive symptom of hypothyroidism. Similarly, comparing the frequency of weight gain $(58 \%)$ and BMI >2SD (38\%) in our group of SH patients, it can be concluded that it is not obesity, but fast weight gain that is typical of hypothyroidism.

The next observation concerns goiter. It seems to be a strange finding that goiter occurence is so rare and not of very high volume in $\mathrm{SH}$ children under such a strong stimulation of extremely increased TSH (Table 2). In the literature, there is evidence that some patients with atrophic AIT could be positive for anti-TSHR ab $(13,14)$ that act as TSH-blocking factors. They are usually polyclonal and bind to the leucine-rich repeat region of the extracellular domain of the TSHR, similar to stimulating antibodies present in patients with Graves' disease $(15,16)$. Blocking antibodies cut off the signal pathway of TSHR, and this can cause atrophic changes in the thyroid gland. Nevertheless, in our group, the number of patients in whom anti-TSHR ab were determined was too small to make reliable conclusions. In our opinion, in hypothyroid patient without goiter, anti-TSHR antibodies should be the obvious element of laboratory workshop.

For the last 10 years, reports evaluating large groups of children with severe hypothyroidism have been scanty and most of them concern cases with some unusual manifestations. Cabrera et al. (17) reported a relatively large group of 62 children with severe primary hypothyroidism. In this group, eight (24\%) patients at prepubertal age experienced pseudoprecocious puberty with such symptoms as thelarche and/or menarche in girls and isolated testicular enlargement in boys, which regressed 
during the thyroid hormone replacement. In de Vries et al., the group of 114 children and adolescents with autoimmune thyroiditis reported normal onset and duration of puberty; however, in their study, only 40 children were hypothyroid with TSH value between 11.8 and $236 \mathrm{mIU} / \mathrm{l}$ (18). In our study also, none of the patients presented symptoms of precocious puberty. The only abnormality related to puberty in our group was excessive menstrual bleeding in one girl at the age of 14.7 years. It is a typical symptom of hypothyroidism in menstruating girls, which is connected with impaired production of coagulation factors in the liver (19). Additionally, primary hypothyroidism is often associated with increased prolactin level, which can cause puberty arrest and oligomenorrhea or secondary amenorrhea. Khawaja et al. reported 16 patients younger than 20 with severe hypothyroidism (TSH $>50 \mathrm{mIU} / \mathrm{l})$ where two girls presented precocious puberty with precocious menarche and breast development with prepubertal response to gonadotropinreleasing hormone stimulation test (20).

Skin symptoms present in our patients, such as myxedema, dry, rough skin as well as loss of head hair are widely known as symptoms of hypothyroidism and are easily identified by patients and doctors. As an unusual skin symptom presented by SH children, we consider substantial hypertrichosis of individual intensity, which disappeared in the course of thyroid hormone treatment. Hypertrichosis accompanied by hair loss has been reported in hypothyroid patients (21). The question is why the same patient can suffer loss of head hair and, simultaneously, significant hypertrichosis on other skin areas. To explain this phenomenon, one has to take into account the fact that skin symptoms are dependent not only on thyroid hormone deficiency, but also on excessive TSH level. Thyroid hormone receptor Beta 1 has been proved to be expressed in the human hair follicle (22), but also TSHR messenger RNA (mRNA) and protein have been detected in human scalp hair follicles (23). Western blot and immunohistochemical analyses of skin specimens have confirmed the presence of TSHR protein in keratinocytes and fibroblasts (24). Moreover, it has been found that TSH treatment can induce the proliferation of cultured keratinocytes and fibroblasts (24). We can presume that the hypertrichosis observed in $\mathrm{SH}$ children could be dependent on prolonged TSH excess, whereas the head hair loss could rather result from thyroid hormones deficiency.

It is worthy to notice that in our group of SH children, at the moment of diagnosis none have the associated autoimmune comorbidities such as celiac disease, adrenal insufficiency, or diabetes mellitus, which is often observed in adult patients with Hashimoto's thyroiditis. Our data are concordant with observation of Ruggeri et al. (25), who reported that association between HT and other autoimmune diseases increases with age and occurs most frequently in adults.

\section{Laboratory Characteristics}

It is widely known that anemia is associated with hypothyroidism (26). Its prevalence in adults has been reported at $14-43 \%$ in overt hypothyroidism $(26,27)$. The evaluation of vitamin B12, iron, and folic acid levels in hypothyroid patients with anemia has not revealed any significant differences $(26,27)$. In our group of $\mathrm{SH}$ children, anemia was present with similar frequency (38\%), although one might have expected a higher prevalence in severe hypothyroidism. The positive correlation of TSH level and MCV in our study supports the hypothesis of Das et al. (28), which suggests that the basic background of anemia in hypothyroidism is a deficiency of erythropoietin dependent on thyroid hormone deficiency. Nevertheless, the differences in the values of $\mathrm{Hgb}, \mathrm{MCV}$, and $\mathrm{RBC}$ among our patients also suggest that the pathophysiology of anemia in hypothyroidism is much more complicated and must have various reasons including iron deficiency in some cases.

Hypothyroidism is closely associated with abnormal liver function resulting in atherogenic lipid profile and elevated aminotransferases. Liver function tests return to normal during thyroid hormone replacement (29). Nevertheless, increased prevalence of non-alcoholic fatty liver disease in hypothyroid adults with abnormal alanine aminotransferase according to the grade of hypothyroidism has been reported (30).

In our study, we found an increase of cholesterol and its fractions in $\mathrm{SH}$ patients, but we did not observe any evident correlations of lipid parameters with the TSH level. On the contrary, very clear associations were found between fT4 or fT3 concentrations and lipid profile. We suppose that perhaps extremely increased TSH values should be evaluated for statistical use in logarithmic scale, because the deviations of TSH values in our study were very high in comparison to deviations in lipids concentrations. In our group of SH children, aminotransferases were elevated in the majority of patients in whom they were measured $(n=23)$. We observed a preponderance of AST elevation: it was detected in $82 \%(n=19)$ of children and ALT increased in 65\% $(n=15)$ (Tables 1,3$)$. The value of TSH correlated positively only with AST concentration. Most authors suggest that more frequent AST than ALT elevation in hypothyroidism results from associated myopathy, not only the liver injury (30). On the other hand, other factors could also be involved in pathomechanism of the injury, including oxidative stress and decreased ceruloplasmin level, which is reported in hypothyroid patients $(31,32)$.

Myopathy and rhabdomyolysis have been reported as the factors partially responsible for the increase of creatinine, which is released from muscles (33). Serum creatinine elevation has been observed in adults as well as in children with hypothyroidism (34). This change can normalize during the treatment with thyroxine; however, in a long-standing study by Elgadi et al. (35), the authors suggest that renal impairment induced by hypothyroidism in children is not as benign as has been previously considered. In their study, GFR did not normalize completely even after 5 years of thyroxine therapy in some patients (35).

In our group of $\mathrm{SH}$ children, creatinine concentration was elevated in four patients, but calculated GFR was decreased in 11 children and was determined only in 15 out of 26 patients. It shows that this is not considered a routinely examined parameter in hypothyroid patients. The pathomechanism of renal impairment in hypothyroidism is not fully understood. It is suggested that thyroid hormones have an influence on muscle 
function, circulating volume, and cardiac function, and also have a direct effect on the kidney (36).

\section{Imaging}

\section{Bone Age}

In general experience, BA in hypothyroidism is delayed proportionally to the grade and duration of thyroid hormones deficiency. In our group, the BA was determined in patients with significant height deficiency (below third percentile) and we had a unique opportunity to observe monozygotic twin girls at the age of 8.5 years with severe hypothyroidism with a different delay of BA ( 3 and 5 years, respectively) (Table 2). They had similar thyroid hormone deficiency, but the duration of hypothyroidism was longer in the girl with greater BA delay.

\section{Thyroid Ultrasonography}

In ultrasound scans, thyroid glands in our patients were hypoechogenic, 11 out of 26 patients $(42 \%)$ had goiter, and a small thyroid was found in three children (11.5\%). Thyroid blood perfusion was increased in $53.8 \%$, and reduced in $11.5 \%$. Nodules or focal changes were present only in two out of $26 \mathrm{SH}$ children. They were of benign character.

\section{Pituitary MRI}

An interesting finding was pituitary hyperplasia found in four $\mathrm{SH}$ children suffering from headaches. One of those four children also had seizures. The incidence of pituitary hyperplasia secondary to hypothyroidism is unknown and probably underestimated. Pituitary MRI in patients with hypothyroidism is recommended only when some suggestive symptoms are present, i.e., vision disturbances, seizures, or severe headaches. A recent review of literature by Cao et al. (37) reported only 17 pediatric cases published from 1980 to 2017 (retrieved from Pubmed). On the other hand, Shukla et al. (38) published a review of pituitary hyperplasia in adult patients with hypothyroidism, which suggests that it is an underestimated problem and the frequency of pituitary hyperplasia has not been clearly identified. Khawaja et al. (20) reported that pituitary enlargement is observed in $70 \%$ of patients with TSH value $>50$ $\mathrm{mIU} / \mathrm{L}$ and in $84 \%$ of patients with TSH higher than $100 \mathrm{mIU} / \mathrm{L}$. Additionally the authors suggested that in younger patients, the frequency of pituitary enlargement can be even higher, but in their study there were only 16 patients below 20 years of life (20).

In our group of $\mathrm{SH}$ children, the MRI was performed only in four out of 26 children and the indications for this examination were headaches or neurological symptoms, not hypothyroidism. In these four children, everyone had an enlarged anterior pituitary and the function of tropic hormones secreted in pituitary was not impaired (Supplementary Table 1).

In $\mathrm{SH}$ patients, a deep deficiency of thyroid hormones causes excessive over-secretion of thyrotropin-releasing hormone (TRH) resulting in hypersecretion of $\mathrm{TSH}$ and prolactin. Increased prolactin and enlarged pituitary can suggest false pituitary adenoma, moreover the overlapping clinical symptoms such as growth arrest and weight gain associated with pituitarysuprasellar tumors could be differentiated with other childhood suprasellar tumors, i.e., craniopharyngioma. The differential diagnostics can be easy considering thyroid tests results because patients with craniopharyngioma typically present secondary and not primary hypothyroidism. More difficult could be the differentiation from prolactinoma. Another problem is not to overlook TSH-secreting adenomas, which were sporadically reported in patients with severe longstanding hypothyroidism due to the possible autonomisation of thyrotrophs $(39,40)$. Histology studies in humans revealed some characteristic changes of pituitary cells known as "thyroidectomy cells" (41) and additionally, it is suggested that thyrotroph hyperplasia is attributed to a loss of inhibitory feedback of the hypothalamopituitary axis (42). In concert to these findings, it could be presumed that patients without goiter positive for blocking anti-TSHR ab might be particularly predisposed to pituitary enlargement because of the interference of these antibodies with the ultrashort loop (TSH-pituitary) (43), which could additionally enhance the pituitary enlargement.

\section{FINAL CONCLUSIONS}

In children with severe hypothyroidism, the most sensitive symptoms are growth arrest and weight gain, despite the fact that, in some children, the auxological parameters at presentation could be within normal values for the population. The specific biochemical profile is closely correlated with severity of thyroid hormone deficiency and involves mostly erythropoiesis, liver function, and kidney function. Pituitary enlargement should be considered in each child with severe hypothyroidism. It is necessary to conduct prospective studies evaluating the actual frequency of anti-TSHR antibodies and pituitary enlargement in children with extremely high TSH, especially without goiters.

\section{DATA AVAILABILITY STATEMENT}

All datasets presented in this study are included in the article/Supplementary Material.

\section{ETHICS STATEMENT}

The studies involving human participants were reviewed and approved by Bioethics Committee at the Medical University of Warsaw. Written informed consent to participate in this study was provided by the participants' legal guardian/next of kin.

\section{AUTHOR CONTRIBUTIONS}

AK designed the study, wrote, and supervised the manuscript. EW-S performed statistical analysis and wrote the manuscript. $\mathrm{DL}$ and MR recorded data of the patients, wrote the manuscript, and collected the literature data. All authors have read and approved the manuscript.

\section{SUPPLEMENTARY MATERIAL}

The Supplementary Material for this article can be found online at: https://www.frontiersin.org/articles/10.3389/fendo. 2020.00364/full\#supplementary-material 


\section{REFERENCES}

1. Cappa M, Bizzarri C, Crea F. Autoimmune thyroid diseases in children. J Thyroid Res. (2010) 2011:675703. doi: 10.4061/2011/675703

2. Hunter I, Greene SA, MacDonald TM, Morris AD. Prevalence and aetiology of hypothyroidism in the young. Arch Dis Child. (2000) 83:207-10. doi: $10.1136 /$ adc.83.3.207

3. Aversa T, Corica D, Zirilli G, Pajno GB, Salzano G, De Luca F, et al. Phenotypic expression of autoimmunity in children with autoimmune thyroid disorders. Front Endocrinol. (2019) 10:476. doi: 10.3389/fendo.2019. 00476

4. Ajjan RA, Weetman AP. The pathogenesis of Hashimoto's thyroid-itis: further developments in our understanding. Horm Metab Res. (2015) 47:702-10. doi: $10.1055 / \mathrm{s}-0035-1548832$

5. Wassner AJ. Pediatric hypothyroidism: diagnosis and treatment. Paediatr Drugs. (2017) 19:291-301. doi: 10.1007/s40272-0170238-0

6. Pearce EN. Update in lipid alterations in subclinical hypothyroidism. J Clin Endocrinol Metab. (2012) 97:326-333. doi: 10.1210/jc.20112532

7. Floriani C, Feller M, Aubert CE, M'Rabet-Bensalah K, Collet TH, den Elzen WPJ, et al. Thyroid dysfunction and anemia: a prospective cohort study and a systematic review. Thyroid. (2018) 28:575-82. doi: 10.1089/thy.2017.0480

8. Wopereis DM, Du Puy RS, van Heemst D, Walsh JP, Bremner A, Bakker SJL, et al. Thyroid studies collaboration. the relation between thyroid function and anemia: a pooled analysis of individual participant data. J Clin Endocrinol Metab. (2018) 103:3658-67. doi: 10.1210/jc.2018-00481

9. Malespin M, Nassri A. Endocrine diseases and the liver: an update. Clin Liver Dis. (2019) 23:233-46. doi: 10.1016/j.cld.2018.12.006

10. Ellervik C, Mora S, Ridker PM, Chasman DI. Hypothyroidism and kidney function: a mendelian randomization study. Thyroid. (2020) 30:365-79. doi: 10.1089/thy.2019.0167

11. Greulich WW, Pyle SI. Radiographic Atlas of Skeletal Development of the Hand and Wrist. 2nd ed. Stanford, CA: Stanford University Press (1959). doi: 10.1097/00000441-195909000-00030

12. Staples A, LeBlond R, Watkins S, Wong C, Brandt J. Validation of the revised Schwartz estimating equation in a predominantly non-CKD population. Pediatr Nephrol. (2010) 25:2321-6. doi: 10.1007/s00467-010-1598-7

13. Kahaly GJ, Diana T, Glang J, Kanitz M, Pitz S, König J. Thyroid stimulating antibodies are highly prevalent in hashimoto's thyroiditis and associated orbitopathy. J Clin Endocrinol Metab. (2016) 101:1998-2004. doi: 10.1210/jc.2016-1220

14. Feingold SB, Smith J, Houtz J, Popovsky E, Brown RS. Prevalence and functional significance of thyrotropin receptor blocking antibodies in children and adolescents with chronic lymphocytic thyroiditis. J Clin Endocrinol Metab. (2009) 94:4742-8. doi: 10.1210/jc.2009-1243

15. Nagayama Y, Rapoport B. The thyrotropin receptor 25 years after its discovery: new insight after its molecular cloning. Mol Endocrinol. (1992) 6:145-56. doi: $10.1210 /$ me.6.2.145

16. Kraiem Z, Lahat N, Glaser B, Baron E, Sadeh O, Sheinfeld M. Thyrotrophin receptor blocking antibodies: incidence, characterization and in-vitro synthesis. Clin Endocrinol. (1987) 27:409-21. doi: 10.1111/j.1365-2265.1987.tb01168.x

17. Cabrera SM, DiMeglio LA, Eugster EA. Incidence and characteristics of pseudoprecocious puberty because of severe primary hypothyroidism. $J$ Pediatr. (2013) 162:637-9. doi: 10.1016/j.jpeds.2012.10.043

18. De Vries L, Bulvik S, Phillip M. Chronic autoimmune thyroiditis in children and adolescents: at presentation and during long-term follow-up. Arch Dis Child. (2009) 94:33-7. doi: 10.1136/adc.2007.134841

19. Poppe K, Velkeniers B, Glinoer D. Thyroid disease and female reproduction. Clin Endocrinol. (2007) 66:309-21. doi: 10.1111/j.1365-2265.2007. 02752.x

20. Khawaja NM, Taher BM, Barham ME, Naser AA, Hadidy AM, Ahmad AT, et al. Pituitary enlargement in patients with primary hypothyroidism Endocr Pract. (2006) 12:29-34. doi: 10.4158/EP.12.1.29

21. Ai J, Leonhardt JM, Heyman WR. Autoimmune thyroid disease: etiology, pathogenesis and dermatological manifestation. J Am Acad Dermatol. (2003) 48:641-56. doi: $10.1067 / \mathrm{mjd} .2003 .257$
22. Billoni N, Buan B, Gautier B, Gaillard O, Mahe YF, Bernhard BA Thyroid hormone receptor b1 is expressed in the human hair follicle. Br J Dermatol. (2000) 142:645-52. doi: 10.1046/j.1365-2133.2000. 03408.x

23. Bodó E, Kromminga A, Bíró T, Borbíró I, Gáspár E, Zmijewski MA, et al. Human female hair follicles are a direct, nonclassical target for thyroid-stimulating hormone. J Invest Dermatol. (2009) 129:1126-39. doi: 10.1038/jid.2008.361

24. Cianfarani F, Baldini E, Cavalli A, Marchioni E, Lembo L, Teson $\mathrm{M}$, et al. TSH receptor and thyroid-specific gene expression in human skin. J Invest Dermatol. (2010) 130:93-101. doi: 10.1038/jid. 2009.180

25. Ruggeri RM, Trimarchi F, Giuffrida G, Certo R, Cama E, Campennì A, et al. Autoimmune comorbidities in Hashimoto's thyroiditis: different patterns of association in adulthood and childhood/adolescence. Eur J Endocrinol. (2017) 176:133-41. doi: 10.1530/EJE-160737

26. M'Rabet-Bensalah K, Aubert CE, Coslovsky M, Collet TH, Baumgartner C, den Elzen WPJ, et al. Thyroid dysfunction and anaemia in a large population-based study. Clin Endocrinol. (2016) 84:627-31. doi: 10.1111/cen. 12994

27. Erdogan M, Kösenli A, Ganidagli S, Kulaksizoglu M. Characteristics of anemia in subclinical and overt hypothyroid patients. Endocr J. (2012) 59:213-20. doi: 10.1507/endocrj.EJ11-0096

28. Das KC, Mukherjee M, Sarkar TK, Dash RJ, Rastogi GK. Erythropoiesis and erythropoietin in hypo- and hyperthyroidism. J Clin Endocrinol Metab. (1975) 40:211-20. doi: 10.1210/jcem-40-2-211

29. Burra P. Liver abnormalities and endocrine diseases. Best Practice Res Clin Gastroenterol. (2013) 27:553-63. doi: 10.1016/j.bpg.2013. 06.014

30. Chung GE, Kim D, Kim W, Yim JY, Park MJ, Kim YJ, et al. Non-alcoholic fatty liver disease across the spectrum of hypothyroidism. J Hepatol. (2012) 57:150-6. doi: 10.1016/j.jhep.2012.02.027

31. Bhattacharya A, Saha, R, Mondal T, Choudhuri S, Gupta S. Ceruloplasmin and serum MDA levels in hypothyroid patients. Int J of Biomed Adv Res. (2014) 5:369-72. doi: 10.7439/ijbar.v5i8.832

32. Valenzise M, Porcaro F, Zirilli G, De Luca F, Cinquegrani M, Aversa T. Hypoceruloplasminemia: an unusual biochemical finding in a girl with Hashimoto's thyroiditis and severe hypothyroidism. Pediatr Med Chir. (2018) 40. doi: 10.4081/pmc.2018.179

33. Comak E, Koyun M, Kiliçarslan-Akkaya B, Bircan I, Akman S. Severe rhabdomyolysis and acute renal failure in an adolescent with hypothyroidism. Turk J Pediatr. (2011) 53:586-9.

34. den Hollander JG, Wulkan RW, Mantel MJ, Berghout A. Correlation between severity of thyroid dysfunction and renal function. Clin Endocrinol. (2005) 62:423-7. doi: 10.1111/j.1365-2265.2005.02236.x

35. Elgadi AE, Verbovszki P, Berg UB. Long-term effects of primary hypothyroidism on renal function in children. J Pediatr. (2008) 152:860-4. doi: 10.1016/j.jpeds.2007.10.050

36. Kimmel M, Braun N, Alscher MD. Influence of thyroid function on different kidney function tests. Kidney Blood Press Res. (2012) 35:9-17. doi: 10.1159/000329354

37. Cao J, Lei T, Chen F, Zhang C, Ma C, Huang H. Primary hypothyroidism in a child leads to pituitary hyperplasia: a case report and literature review. Medicine. (2018) 97:e12703. doi: 10.1097/MD.00000000000 12703

38. Shukla P, Bulsara K, Luthra P. Pituitary hyperplasia in severe primary hypothyroidism: a case report and review of the literature. Case Rep Endocrinol. (2019) 2019:ID2012546. doi: 10.1155/2019/20 12546

39. Langlois MF, Lamarche JB, Bellabarba D. Long-standing goiter and hypothyroidism: an unusual presentation of a TSH-secreting adenoma. Thyroid. (1996) 6:329-35. doi: 10.1089/thy.1996.6.329

40. Marucci G, Faustini-Fustini M, Righi A, Pasquini E, Frank G, Agati R, et al. Thyrotropin-secreting pituitary tumours: significance of "atypical adenomas" in a series of 10 patients and association with Hashimoto thyroiditis as a cause of delay in diagnosis. J Clin Pathol. (2009) 62:455-9. doi: $10.1136 /$ jcp. 2008.061523 
41. Alkhani AM, Cusimano M, Kovacs K, Bilbao JM, Horvath E, Singer W. Cytology of pituitary thyrotroph hyperplasia in protracted primary hypothyroidism. Pituitary. (1999) 1:291-5. doi: 10.1023/A:10099668 12195

42. Eiland L, Oyesiku NM, Ritchie JC, Isaacs S, Ioachimescu AG. Pathogenesis of marked pituitary enlargement and increased serum thyroid-stimulating hormone in primary hypothyroidism. Thyroid. (2012) 22:101-2. doi: $10.1089 /$ thy.2011.0237

43. Prummel MF, Brokken LJ, Wiersinga WM: Ultra short-loop feedback control of thyrotropin secretion. Thyroid. (2004) 14:825-9. doi: $10.1089 /$ thy.2004.14.825
Conflict of Interest: The authors declare that the research was conducted in the absence of any commercial or financial relationships that could be construed as a potential conflict of interest.

Copyright $\odot 2020$ Kucharska, Witkowska-Sẹdek, Labochka and Rumińska. This is an open-access article distributed under the terms of the Creative Commons Attribution License (CC BY). The use, distribution or reproduction in other forums is permitted, provided the original author(s) and the copyright owner(s) are credited and that the original publication in this journal is cited, in accordance with accepted academic practice. No use, distribution or reproduction is permitted which does not comply with these terms. 